Original Article

\title{
Risk, recessions and the resilience of the capitalist economies
}

\author{
Paul Ormerod \\ Volterra Consulting, London and Institute of Advanced Study, University of \\ Durham, UK. \\ E-mail: pormerod@volterra.co.uk
}

\begin{abstract}
The ability to predict overall developments in the economy is extremely limited, even just 1 year ahead. The track record of forecasting is very poor, especially immediately before or during recessions, in other words exactly when good forecasts are needed most by policy-makers. The aims of this paper are to establish stylised facts on the duration and size of recessions, which can be used by policy-makers in assessing macroeconomic risks. In addition, models of the business cycle in economic theory need to be able to replicate these facts. Evidence is taken from 17 Western economies over a long period of time, from 1871 to 2007. Two definitions of recession are used, and the results are robust with respect to the definitions. The striking feature of the data is the resilience of the economies. The clear majority of recessions lasts for just a single year, and only a small minority persists for more than 2 years. However, in terms of both size and duration, the bigger the recession and the longer it has persisted, the less likely recovery becomes. This is not consistent with the assumption made in mainstream macroeconomic theory that business fluctuations are driven by recurring identically independently distributed random shocks.

Risk Management (2010) 12, 83-99. doi:10.1057/rm.2009.3
\end{abstract}

Keywords: economic recessions; resilience; Weibull distribution

\section{Introduction}

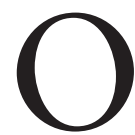

ver the course of the twentieth century as a whole, the annual average growth rate of real GDP in the main Western economies was typically between 2 and 3 per cent, slightly higher in a few of the economies. This steady growth is the feature of capitalism, which is strikingly different to all previous and existing alternative systems of economic organisation. 
Around the path of slow but steady growth, however, are persistent short-term fluctuations in growth rates. Some of these have been dramatic. In the Great Depression in America in the early 1930s, for example, real output fell by some 30 per cent and almost one in every four Americans lost their jobs.

Policy-makers, whether in the public or private sectors, would like to have reasonably accurate forecasts of short-term developments in the economy as a whole, in order to assess the risks which might be posed to their objectives. However, the track record of economic forecasting of the overall economy, even just 1 year ahead, is poor.

During recessions, the overall level of economic activity falls, posing risks to the very survival of many companies, as the current events illustrate. In the most recent decades in the Western economies, aggregate economic data on GDP is available on a quarterly basis, and the conventional definition of a recession has come to mean two successive quarters in which the growth rate of GDP is negative. In many countries, however, quarterly data are a relatively recent innovation, and only in a minority of Western economies are quarterly data available even back to the late 1940s. No official quarterly data are available before World War II. The more general definition of a recession is therefore, using annual data, a year in which GDP growth is negative.

In early 2008, very few economists predicted what was about to happen, and almost all published forecasts envisaged positive economic growth during 2009. Fildes and Stekler, 2002, and McNees, 1992, for example, provide more systematic assessments of forecasting accuracy. The average error on 1-year ahead GDP forecasts, for example, is somewhat less than the standard error of the data itself, but almost all reasonably accurate forecasts occur when the economy is rather stable. The track record of predicting recessions, when the risks to companies from the overall economic environment are at their highest, is exceptionally bad. Ormerod and Mounfield, 2000, give a potential explanation of this in terms of the signal/noise ratio in the data.

An important reason for this failure to assess the risks of recession is that the causes of recessions are understood at best poorly in economic theory. Mainstream macroeconomic theory posits that cycles are not inherent features of economies, but are caused by exogenous stochastic shocks. This is the case both with real business cycle theory (Kydland and Prescott, 1982), and its more modern development, dynamic stochastic general equilibrium theory (Woodford, 2009, for example). The stochastic element at the heart of such models means that by definition in these theories, successful short-term prediction is at best extremely difficult.

There is a different tradition within economics, going back at least as far as Marx in the mid-nineteenth century, which sees business cycles, the fluctuations around trend growth which include recessions, as endogenous to the Western market economies. On this view of the world, we need not posit external shocks, whatever these might be, to account for the existence of 
recessions, they are an inherent feature of the market-oriented capitalist economies. Although such opinions form a distinct minority within academic economics, their authors include some of the most famous names in economics, Hayek, Keynes and Schumpeter, for example.

However, these theoretical approaches often differ substantially. Further, they have not really been subjected to scientific validation, and so we are simply unable to say which, if any, gives the best account of recessions, or indeed whether any of them are able to replicate the key empirical features of recessions at all.

The purpose of this paper, therefore, is not to consider why recessions happen, but instead to establish some stylised facts on recessions in the Western capitalist economies. For example, how large is the typical fall in output during a recession, and how long do recessions last? Are large and/or long recessions quantitatively or qualitatively different from small and/or short ones? Do recessions become more or less likely to persist as either their duration or size increases?

An appreciation of such factors will be useful to policy-makers in both the public and private sectors as part of assessing the risks that they face.

The next section discusses both the definitions of recession and the data that are used. The next following section sets out an overview of the data. A more detailed analysis is carried out in the subsequent section.

\section{Data and Definitions}

I take a long perspective, and consider the experiences of a broad range of Western economies since the late nineteenth century, the period by which they could all reasonably be regarded as industrial rather than agricultural economies. The main data source is the annual real GDP data for 17 Western economies available from 1870 to 1994 in Maddison, 1995. ${ }^{1}$ Data over the 1995-2007 period are from the IMF database. (Strictly speaking, the two sources are not exactly comparable because the Maddison data is in real Geary-Khamis dollars and the IMF in real domestic currency, but given that the definition of a recession involves the growth rate of GDP, this is of little consequence.) The data are available in an Excel file on application to the author.

The conventional definition of a recession, using annual data, is a year in which the rate of growth of real GDP is less then zero A more sophisticated approach to defining a recession is that of the National Bureau of Economic Research (NBER), ${ }^{2}$ where a team of distinguished economists apply judgement to a wider series of economic indicators in order to define a period of recession, which can be summarised as a 'period of significant decline in economic activity'. The main indicator they use is in fact GDP, but they take into account 
other variables such as employment. The conventional approach and that of the NBER usually give the same result. But NBER-type indicators are not generally available for some of the countries in the data set, and even when they are, relate only to the decades at the end of the twentieth century.

So the analysis is carried out using the standard definition. The duration of a recession is the number of consecutive years in which real GDP growth is less than zero. The size of a recession is the cumulative percentage fall in GDP during these years.

As a check on robustness, I also examine the data using an alternative definition, in which a recession is defined as being the entire period over which real GDP remains below its previous peak level. In other words, even when positive growth is resumed, the level of GDP can still be below the previous peak, and on this definition, such years are counted as recession years. The size of the recession on this definition is the cumulative percentage fall in GDP below its previous peak value.

\section{Overview of the Data}

The basic data have information on recessions in 17 countries, and this is pooled to form the data set used in the analysis. As a first step, I examine the potential heterogeneity of the pooled data, specifically whether the distribution of the size of recessions varies across countries.

Kolmogorov-Smirnov tests are carried out $^{3}$ of the null hypothesis that the distribution of the size of recessions is the same between every pair of countries in the data set. The sample size in each of these pair-wise tests is small, but the Matlab manual states for the $\mathrm{K}-\mathrm{S}$ test that 'the asymptotic $P$-value becomes very accurate for large sample sizes, and is believed to be reasonably accurate for sample sizes $N 1$ and $N 2$ such that $(N 1 \times N 2) /(N 1+N 2) \geqslant 4$ '. The range of values for this expression in the pair-wise tests is $5.5-10.24$.

The full sample, 1871-2007, is used in order to maximise the number of observations for each country. There are 136 such pair-wise tests, and the null hypothesis is rejected at a $P$-value of less than 0.05 in only five cases. In other words, the null hypothesis that the two distributions are the same is only rejected at the conventional level of statistical significance in five out of 136 cases. It is therefore reasonable to assume that the pooled data across countries are homogeneously distributed.

This is a useful finding in itself, for two reasons. First, and more importantly, it suggests that there are features that are common to recessions across countries. Given that the hypothesis is not rejected that the statistical distribution of the cumulative sizes of recessions is the same across all countries. In principle, therefore, a general theoretical model can explain recessions, which is the presumption of economic theory. Second, certain aspects of the 
statistical analysis of the data would become more problematic if the pooled data contained heterogeneity across countries.

In total, there have been 255 examples of recessions over the 1870-2007 period as a whole. The duration in years is set out in Table 1.

The striking feature of the duration data is that approximately two-thirds of all recessions last only a single year, using the conventional definition of a recession. The Western economies therefore appear prima facie to be able to recover quickly after an initial shock.

The sample period, both in terms of time and country, embraces a very wide variety of different approaches to economic policy by individual governments and international bodies. So it is unlikely that rapid and successful policy responses are the reason why the typical recession is of such short duration. It is more reasonable to postulate that this is an inherent feature of how the economies operate.

The resilience of the capitalist economies is further illustrated by the recovery patterns of the economies devastated by the World Wars, and in particular the defeated powers in World War II.

There are nine truly extreme shocks, each with cumulative output falls of more than 30 per cent, three of which relate to the World War I period and the other six to World War II. In each case, with the exception of France 1917-1918, the falls took place in the defeated countries. In 1945, for example, much of Japan was destroyed by both atomic and conventional bombing. Germany was both heavily bombed and subjected to intense land fighting on its territory.

Real GDP in Japan fell by 50 per cent in 1945, for example, and in Germany by 29 per cent followed by a 41 per cent fall in 1946, a cumulative fall of 58 per cent. Yet in both these countries positive economic growth resumed very rapidly, in 1946 and 1947, respectively, and the pre-war (1938) levels of real GDP were reached in 1951. The next recession year in Japan was 1974 and in Germany 1975, so after devastating shocks, the two countries registered almost 30 years of unbroken economic growth.

In Italy, the other main defeated power in World War II, GDP fell by 9 per cent in 1943, a further 19 per cent in 1944, with yet another drop of 22 per cent in 1945, a cumulative fall of 44 per cent. Yet, real GDP had risen

Table 1: Duration of recession years, that is number of consecutive years in which real GDP growth is less than zero

\begin{tabular}{lrrrrrrr}
\hline \multicolumn{7}{c}{ Years } \\
\hline \multirow{2}{*}{ Number } & 1 & 2 & 3 & 4 & 5 & 6 & 7 \\
\hline
\end{tabular}


to its 1938 level by 1949. In Austria, output fell by no less than 59 per cent in 1945 as the Red Army overran the country, yet passed its 1938 level in 1950. France suffered a cumulative fall of 53 per cent during its occupation 1940-1944, yet started to grow in 1945 and recovered its 1938 level by 1949 .

The recovery of these economies is often attributed to the enlightened policies of the United States, such as the Marshall Plan and the agreements on international trade and monetary affairs, although Matthews (1968) offers a coherent account of post-war experience based on pure supply-side factors such as profitability.

The experience after World War I stands in marked contrast in terms of economic policy, there being no single imperial power able to impose a postwar settlement of the kind, which America did after World War II. Indeed, the inter-war period as a whole exhibits a marked lack of cooperation on international economic affairs.

The three main combatants, France, Germany and the United Kingdom experienced substantial losses of skilled manpower, traumatic psychological stress and significant internal conflicts both towards the end of, and after the war. These years were marked by large falls in real GDP in all three countries, 12 per cent in Germany, 23 per cent in the United Kingdom and 33 per cent in France. But even after these deep recessions, France recovered its pre-war 1913 level by 1923, and both Germany and the United Kingdom achieved this by 1925.

A summary of the size distribution of recessions over the sample as a whole is given in Table 2. The information is given both for the full 1871-2007 period, and for the same period but excluding the war-affected years 1914-1919 and 1939-1947.

In both cases, the right-skew nature of the distribution is clear, with the mean being distinctly higher than the median.

Essentially, the war-related years just stretch out the tail of the data, because the null hypothesis that the distributions of the size data including and excluding the war-related years is the same is only rejected at a $P$-value of 0.206 on a Kolmogorov-Smirnov test. The conventional level of rejection of the null hypothesis is of course 0.05 and below. The similarity between the two

Table 2: Cumulative size of recessions, per cent fall in real GDP

\begin{tabular}{lcccccc}
\hline & Min & 1st quartile & Median & Mean & 3rd quartile & Max \\
\hline Full sample & 0.01 & 0.94 & 2.88 & 6.26 & 7.33 & 58.7 \\
Excluding & 0.01 & 0.74 & 2.24 & 3.74 & 4.91 & 29.6 \\
1914-1919 and & & & & & & \\
$1939-1947$ & & & & & & \\
\hline
\end{tabular}


Comparison of Empirical cdfs of size and size.exclWW1n2

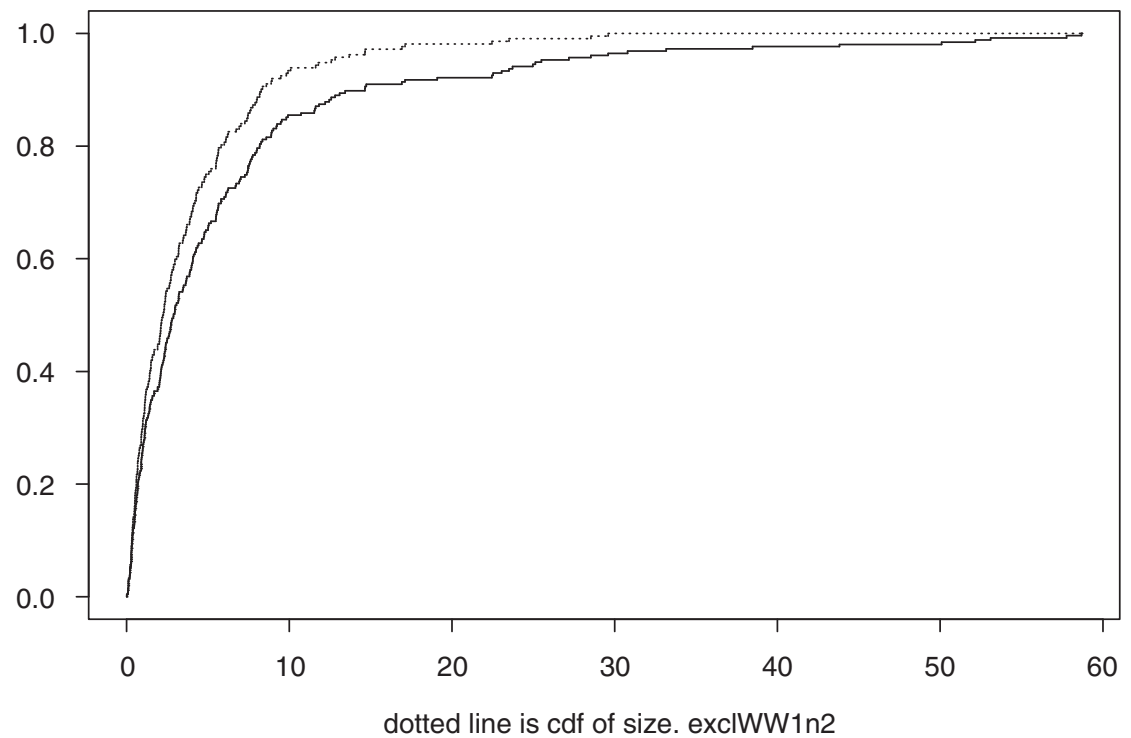

Figure 1: Cumulative distribution function (cdf) of size of recessions, full sample 1870-2007 and excluding 1914-1919 and 1939-1947. The dotted line is the cdf excluding these war related years.

sets of data is shown in Figure 1, which plots their cumulative distribution functions.

\section{More Detailed Analysis}

\section{Duration}

The small number of observations available on the duration of recessions, given that the longest one lasted for just 7 years, limits the ability to carry out formal statistical analysis. In particular, the ability to see if the data are consistent with that of a known statistical distribution.

I used as a benchmark the exponential distribution. This distribution is consistent with the assumption in mainstream macroeconomic theory that business fluctuations are driven by recurring identically independently distributed random shocks, so that the duration of the cycle should be independent of length. (Obviously, however, even if the data were exponential, this does not mean that the theory is necessarily correct, since models with completely different theoretical bases can also generate a distribution of the duration of recessions similar to an exponential, for example, Ormerod, 2004, 2008; Li and Gao, 2006.)

A nonlinear least squares regression ${ }^{4}$ of the frequency against the exponential of the length in years gives the following fit (Table 3): 
Table 3: Duration of recessions and exponential least squares fit

\begin{tabular}{lccccccc}
\hline $\begin{array}{l}\text { Duration: } \\
\text { Years }\end{array}$ & 1 & 2 & 3 & 4 & 5 & 6 & 7 \\
\hline Actual & 164 & 58 & 20 & 6 & 5 & 1 & 1 \\
Fitted & 164 & 58 & 20 & 7 & 3 & 1 & 0 \\
\hline
\end{tabular}

The null hypothesis that the duration follows an exponential distribution with rate parameter of 0.07 is only rejected at a $P$-value of 0.602 on a Kolmogorov-Smirnov test. The small number of observations limits the accuracy of the test, though the $P$-value at which the hypothesis is rejected is very much higher than the conventional level of rejection.

However, the data are perhaps slightly more stretched than a simple exponential (Laherrère and Sornette, 1998, for example). Indeed, a grid search across the scale and shape parameters of the Weibull distribution gives a maximum of the $P$-value at which the null hypothesis is rejected that the data follow that distribution of 0.976. This is distinctly higher than the maximum $P$-value at which the null hypothesis that the data are exponential is rejected.

The value of the shape parameter is 0.61 . With the Weibull distribution, a shape parameter less than 1 implies that the probability of a recession ending is reduced the longer it goes on.

Although the evidence is not conclusive, given that the longest recession was only for 7 years, there is a definite suggestion that exit from recession is not independent of the length of the recession.

\section{Size}

As noted in the Overview of the Data section, the hypothesis that data both including and excluding the war-related years are the same is not rejected. The size data are therefore analysed excluding the war-related years, where the massive recessions experienced arise from military activity and not from the workings of a peace-time economy.

Figure 2 plots the histogram of the cumulative size of the 212 recessions observed during the 1870-2007 period, excluding the war-related years.

Both Table 2 and Figure 2 show clearly the right-skew distribution of the size of recessions. The question is whether the data are compatible with a known statistical distribution.

De Guilmi et al (2003) use a very similar data set in terms of the countries and years and find that the Weibull distribution offers a good approximation to the size of recessions. This is potentially important, because they find that the shape parameter, $\beta$, is greater than 1 , suggesting that the probability of a recession ending increases with its size. However, they define the size of a recession as the sum of consecutive deviations of actual output below potential 


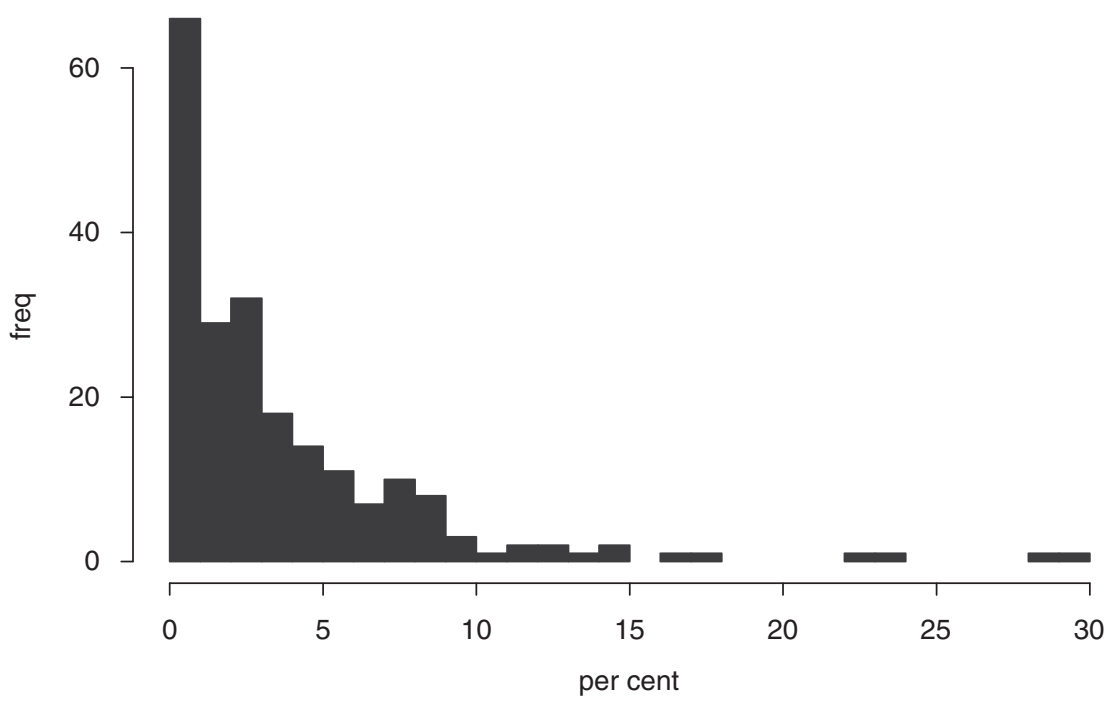

Figure 2: Cumulative percentage fall in output in recessions in 17 Western countries, 1871-2007 excluding war-related years.

output, where potential output is calculated by extracting the trend component from the actual data by means of a Hodrick-Prescott filter. A problem with defining a recession in this way is that years which are characterised as being recession years may also exhibit features not normally associated with a recession, such as rising levels of employment. Observations where the actual growth rate is only slightly below 'potential' will in general have growth above the growth of productivity and hence will exhibit small but positive employment growth.

As it happens, using the definition of a recession as a year in which real GDP growth is less than zero also indicates that the size distribution of recessions is best characterised by a Weibull distribution. I examined the power law distribution, the exponential (a special case of the Weibull in which $\beta=1$ ), and Weibull itself.

The power law has only a poor correspondence with the data, as the simple log-log plot of size against rank in Figure 3 shows clearly. (As is well known, log-log least squares regressions of size and rank can lead to biased estimates of the power law exponent (Goldstein et al, 2004), and alternative estimation methods should be used (Newman, 2005). However, the purpose of the chart is not to estimate the power law exponent but to demonstrate that the relationship is not a power law.) 


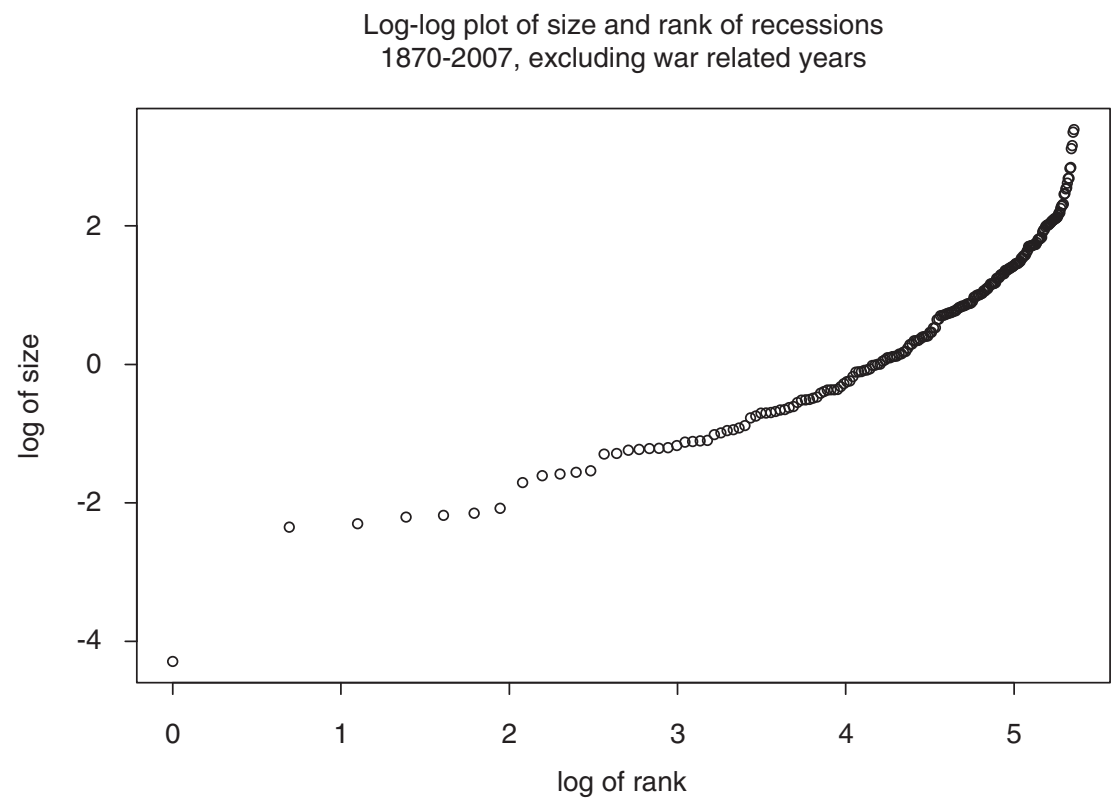

Figure 3: Log-log plot of size and rank of recessions, 1870-2007 excluding war related years. If a power law distribution is a reasonable candidate for the actual distribution of the data, the points will lie approximately on a 45 -degree line in this plot.

In terms of calibrating a Weibull distribution, heterogeneity across the data can bias the shape parameter, $\beta$, downwards (Lancaster, 1979) in a potentially serious way. But the fact that the hypothesis is not rejected that the distributions of the size of recessions across countries are the same, means that this does not present a problem here.

Two approaches were used to calibrate both the exponential and the Weibull distributions to the size data. First, estimation by nonlinear least squares of the appropriate functional form. Second, a grid search of the parameters, which maximise the $P$-value at which the null hypothesis that the actual data and the theoretical distribution are the same, again using the Kolmogorov-Smirnov test.

The exponential is a reasonable approximation to the size data, with the null hypothesis that the data follow such a distribution with rate parameter 0.31 only being rejected at a $P$-value of 0.483 . However, a Weibull with scale parameter 3.284 and shape parameter 0.919 only rejects at a $P$-value of 0.887 . The standard error of the nonlinear least squares exponential fit is 1.523 and for the Weibull it is 0.550 .

The nonlinear least squares estimate of the shape parameter is 0.743 with a standard error of 0.0072 . Figure 4 plots the actual and fitted values from this.

Although the point estimates of the shape parameter differ from each other in the two methods used, 0.743 and 0.919 , they are both less than one. This 
Size of recession, excl. WW1 and WW2, actual and fitted non-linear least squares Weibull estimation

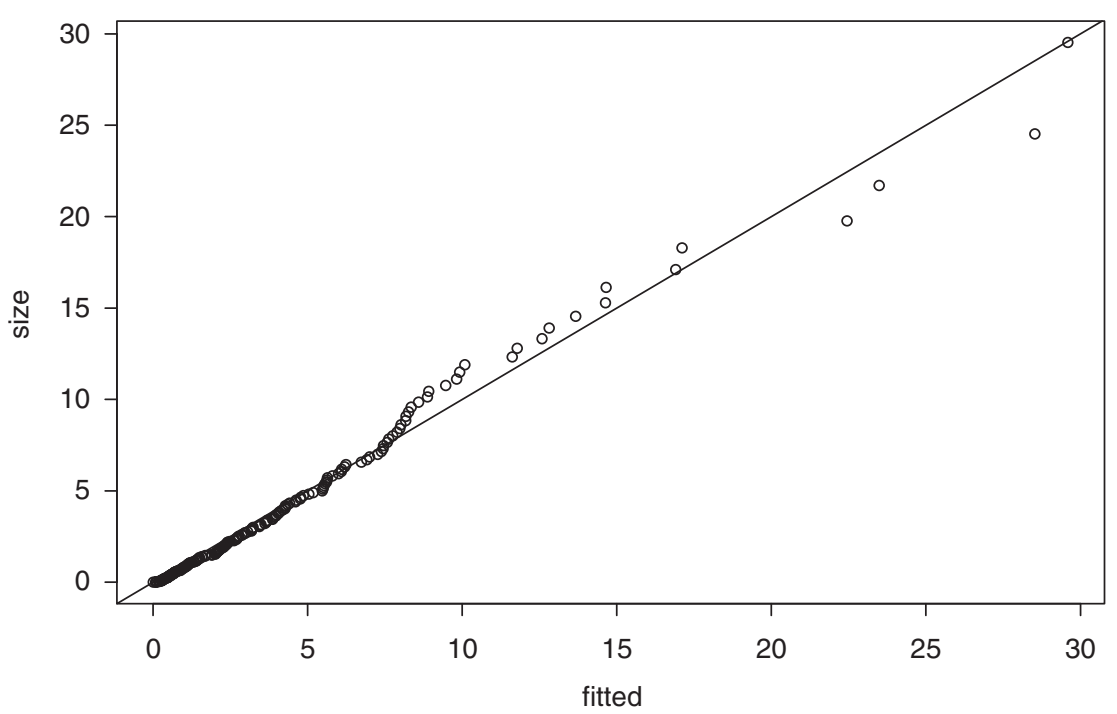

Figure 4: Actual and fitted values of the cumulative size of recessions, 1870-2007 excluding war-related years, Weibull distribution; solid line is the 45 degree line.

implies that, when a recession is defined to be a year in which real GDP growth is less than zero, there is a tendency for recessions to persist the bigger their cumulative size.

The findings on both the size and duration of recessions are compatible with a Keynesian view of recessions in which animal spirits become more depressed the bigger the size of the recession and the longer for which it has gone on.

These results should not obscure the fact that in general the Western economies are very resilient to shocks. In terms of the full data set, 64 per cent of recessions last for only a single year, and excluding the war-related years this percentage rises to 71 .

Further, the percentage of recessions that last just for 1 year is essentially the same regardless of the size of the initial shock.

For example, there are 123 recessions (excluding war-related years) in which the fall in GDP in the initial year was more than 1 per cent. The percentage of these, which ended after 1 year is identical to those where the initial shock is less than 1 per cent, namely 71 per cent. This is perhaps not surprising. But 25 out of the 34 recessions in which the initial fall in GDP was more than 5 per cent - a major shock - also lasted just a single year, or 74 per cent of them. Of the 27 recessions in which the initial fall in GDP was more than 6 per cent, 19 , or 70 per cent, lasted only 1 year. Even in the 11 instances when the initial fall was more than 8 per cent, eight of them lasted just the 1 year. 
So, in general, the capitalist economies exhibit a high degree of resilience, with the substantial majority of recessions lasting over a single year, almost regardless of the initial size of the recession. There is a tendency for recessions that are either very large or long to persist, but these are few in number.

\section{Alternative definition of recession}

On the conventional definition, once GDP growth becomes positive once again, the recession is over. However, it is quite possible that even after the first year of positive growth, the level of real GDP remains below its previous peak. The alternative definition considered here takes account of this. A recession is defined as a period of successive years during which the level of real GDP remains below its previous peak. The size on this definition is the cumulative sum of the percentage differences between the level of GDP in each of the recession years and the level of GDP at its previous peak.

On the conventional definition, the longest recession lasted 7 years. Using the alternative definition, 24 out of the total of 224 recessions lasted longer than 7 years, with two lasting for 15 years and one for 16 years. However, excluding the war years, ${ }^{5}$ only 7 (out of 191) lasted for more than 7 years, the longest being 10 years.

In terms of the size of recessions, measuring this as the cumulative percentage fall in GDP below its previous peak value, some very large values indeed are recorded, principally in the defeated powers in World War II. The largest fall is 289 per cent, compared to 59 per cent on the standard definition. Even excluding the war years, the largest on the alternative definition is still 132 per cent.

However, the null hypothesis that the distributions of both duration and size, respectively, including and excluding the war years are the same cannot be rejected at the conventional $P$-value of 0.05 on a Kolmogorov-Smirnov test. The $P$-values at which the hypothesis is rejected are, respectively, 0.691 and 0.144 . So the data and analysis used below for the alternative definition again excludes the war years.

A comparison of the duration data on the two definitions is set out in Table 4.

Technically, on a Kolmogorov-Smirnov test the null hypothesis that the two distributions are the same is only rejected at $P=0.931$, but there are small sample issues with the test in this context.

Less rigorously, the two certainly exhibit similarities. In particular, the resilience of the economies is again very noticeable. On the standard definition, 71 per cent of recessions last just 1 year and 92 per cent for 1 or 2 years. On the alternative definition, the percentages are, respectively, 59 and 79.

The null hypothesis that the distribution is exponential with rate parameters 0.12 is only rejected at $P=0.808$, but the same test with a Weibull with shape 
Table 4: Duration of recessions, alternative definitions; excluding war-related years

\begin{tabular}{lcc}
\hline Years & $\begin{array}{c}\text { Successive years in which real } \\
\text { GDP growth less than zero }\end{array}$ & $\begin{array}{c}\text { Successive years in which level of real } \\
\text { GDP is below previous peak }\end{array}$ \\
\hline 1 & 147 & 114 \\
2 & 45 & 37 \\
3 & 10 & 15 \\
4 & 3 & 6 \\
5 & 2 & 8 \\
6 & 1 & 2 \\
7 & 0 & 2 \\
8 & 0 & 2 \\
9 & 0 & 4 \\
10 & 0 & 1 \\
\hline
\end{tabular}

Table 5: Cumulative size of recessions, per cent, alternative definitions; excluding war-related years

\begin{tabular}{lcccccc}
\hline & Min & 1st quartile & Median & Mean & 3rd quartile & Max \\
\hline $\begin{array}{l}\text { Successive years in } \\
\text { which real GDP growth }\end{array}$ & 0.01 & 0.75 & 2.24 & 3.73 & 4.91 & 29.6 \\
$\begin{array}{l}\text { less than zero } \\
\begin{array}{l}\text { Successive years in } \\
\text { which level of real GDP } \\
\text { below previous peak }\end{array}\end{array}$ & 0.01 & 0.91 & 2.34 & 8.58 & 6.89 & 132.3 \\
\hline
\end{tabular}

parameter 0.81 is only rejected at an even higher $P$-value of 0.951 . So, again, there is evidence that the duration data are more stretched than that of a simple exponential, and the longer a recession has lasted, the less likely it becomes that it will end.

The size data on the two definitions are in Table 5.

The null hypothesis that the two are the same is rejected at a $P$-value of 0.041 . The data on the alternative definition obviously exhibit considerably more right-skew than the data on the standard definition. On the latter, for example, the mean is 1.67 times the median, and on the former it is 3.67.

However, both are consistent with a Weibull distribution with a shape parameter of less than one. The hypothesis that the data on the alternative definition follow a Weibull rather than an exponential is much clearer than when using the standard definition.

Using the alternative definition of recession, namely the entire period over which real GDP remains below its previous peak level, a grid search of the parameters of a Weibull distribution indicated that with a scale parameter of 4.494 and a shape parameter of 0.761 , the null hypothesis is only rejected at a $P$-value of 0.604 . The null hypothesis that the data follow an exponential is 
rejected at $P$-values considerably below 0.05 . A grid search over the value of the rate parameter shows that the best result is at 0.222 , but even here the null hypothesis is rejected at a $P$-value of 0.028 .

\section{Brief Remarks and Conclusion}

The aim of this paper is to establish stylised facts on the duration and size of recessions in the capitalist economies. The track record of forecasting recessions is extremely poor, so an appreciation of the distribution of the size and length of recessions is important in assessing risks for policy-makers in both the public and private sectors.

Evidence is taken from 17 Western economies over a long period of time, from 1871 to 2007 . By the former date, all these economies can be considered to be essentially industrial rather than agricultural, in other words, modern capitalist economies.

Two definitions of a recession are considered. First, the conventional one of a recession being years in which the growth rate of real GDP is less than zero. Second, years in which the level of real GDP remains below its previous peak value. The qualitative nature of the results is robust with respect to the choice of definition.

A striking feature of the data is the resilience of the economies. The clear majority recessions last for just a single year, and only a small minority persists for more than 2 years.

A plausible reason for this is that most recessions are essentially inventory cycles. During the upswing, businesses tend to become too optimistic about future prospects. As a result, production begins to run ahead of sales and inventory levels rise. Firms then cut back on production in order to restore inventories to more reasonable levels. As part of this process, fixed investment projects may be postponed. Temporary reductions in capital expenditure plus actions to reduce inventory levels are of themselves inherently of short duration. The adjustment takes place quickly.

Of course, this is by no means the only reason for both recessions in general and for any particular recession. Indeed, a key feature of recessions is that detailed examination of them ex-post reveals that each one has its own individual characteristics. The classic illustration of this is the very comprehensive description of all recessions in the United States carried out by Burns and Mitchell in 1946.

Nevertheless, there are sufficient similarities to enable generalisations to be made. For example, the hypothesis that the distributions of the sizes of recessions across the individual countries are the same cannot be rejected at conventional levels of significance. This implies that there are common features underlying the causes of recessions, so that in principle it is possible to develop a theory of the business cycle, which is relevant to all capitalist economies. 
This does not mean that country-specific or indeed recession-specific factors do not exist, but that there is a substantial degree of commonality in the recession experiences of the various capitalist economies.

The assumption is made in mainstream macroeconomic theory that business fluctuations are driven by recurring identically independently distributed random shocks, so that the duration of the cycle should be independent of length. The evidence suggests that this is not the case. Although in general the economies recover from a recession very rapidly, the longer the recession persists, the more likely it is to continue. The distribution of the data is more consistent with a Weibull distribution with shape parameter less than one than it is with an exponential.

The same result is obtained with the distribution of the size of recessions. The bigger the recession, the more likely it is to continue.

These results are not dramatic, but there is good evidence that they exist. They are consistent with Keynes' view that during recessions, 'animal spirits' of entrepreneurs can become depressed to the point where it is not easy for the economy to exhibit spontaneous recovery. Most of the time, the economies do have this property, but the longer and deeper the recession, the less likely recovery becomes.

In terms of the current recession, at the time of writing it appears that there is a distinct risk that it will be severe. In the United States, for example, over the 1996-2006 period annual average growth of real GDP was 3.1 per cent. This slowed to 2.0 per cent in 2007 and to 1.1 per cent in 2008, with GDP falling in the fourth quarter of the year.

Until the second half of 2008, the slow down in growth was of the classic kind involving reductions in inventories and private fixed capital investment. GDP (at 2000 prices) is approximately US\$11 trillion, and between 2006 and 2008 , inventories fell by $\$ 70$ billion and private fixed investment by $\$ 150$ billion. The economy grew overall because of continued increases in personal and public consumption, and by an improvement in the net trade balance.

So the standard conditions that could have brought about a recession in America between 2006 and 2008 - over-optimistic plans of firms - were already in place, and companies reacted to this, again in the standard way. But on top of this we experienced the cataclysmic credit storm in September 2008 whose consequences are still enfolding. Personal sector consumption, by far the biggest single expenditure component of GDP, fell by $\$ 90$ billion between the third and fourth quarters alone.

The current crisis identifies an avenue of future research using this 1871-2008 database, namely that big recessions in terms of both size and duration tend to be associated with financial crises. The difficulty is to obtain an objective assessment across the 17 countries over this entire period of the timings of financial crises, but it is a refinement worth exploring. 


\section{Acknowledgements}

I am grateful for comments from participants at the Winter Organizational

Science conference 2008 at Lake Tahoe, CA, at the Society of Business Economists conference, London 2008 and at the Extreme Events conference at the University of Durham Business School and anonymous referees of Risk Management.

\section{Notes}

1 The countries are Australia, Austria, Belgium, Canada, Denmark, Finland, France, Germany, Italy, Japan, the Netherlands, New Zealand, Norway, Sweden, Switzerland, the United Kingdom and the United States.

2 http://www.nber.org/cycles/recessions.html.

3 Carried out in the statistical package S-Plus using the command ks.gof.

4 Carried out with the command 'nls' in the package S-Plus.

5 The years excluded around World War II on this definition are 1940-1947 rather than 1939-1947, because the Great Depression in both the United States and Austria did not end until 1939 on this definition and this was unequivocally a peace-time recession.

\section{References}

Burns, A.F. and Mitchell, W.C. (1946) Measuring the Business Cycle. Cambridge, MA: NBER.

De Guilmi, C., Gaffeo, E. and Gallegati, M. (2003) Empirical results on the size distribution of business cycle phases. Physica A 333: 325-334.

Fildes, R. and Stekler, H. (2002) The state of macroeconomic forecasting. Journal of Macroeconomics 24(4): 435-468.

Goldstein, M.L., Morris, S.A. and Yen, G.C. (2004) Problems with fitting to the powerlaw distribution. European Physical Journal B 41(2): 255-258.

Kydland, F.E. and Prescott, E.C. (1982) Time to build and aggregate fluctuations. Econometrica 50(6): 1345-1370.

Laherrère, J. and Sornette, D. (1998) Stretched exponential distributions in nature and economy: 'Fat tails' with characteristic scales. European Physical Journal B 2(4): $525-539$.

Lancaster, T. (1979) Econometric methods for the duration of unemployment. Econometrica 47(4): 939-956.

Li, H. and Gao, Y. (2006) A GDP fluctuation model based on interacting firms, http:// arxiv.org/abs/physics/0609046.

Maddison, A. (1995) Monitoring the World Economy 1820-1992. Paris: OECD.

Matthews, R.C.O. (1968) Why has Britain had full employment since the war? Economic Journal 78(311): 555-569.

McNees, S. (1992) How large are economic forecast errors? New England Economic Review (July/August): 25-41.

Newman, M.E.J. (2005) Power laws, Pareto distributions and Zipf's law. arXiv/ $0412004 \mathrm{v} 2$.

Ormerod, P. (2004) Information cascades and the distribution of economic recessions in capitalist economies. Physica A 341: 556-568. 
Ormerod, P. (2008) Global recessions as a cascade phenomenon with heterogeneous, interacting agents. arXiv/0807.1639.

Ormerod, P. and Mounfield, C. (2000) Random matrix theory and the failure of macroeconomic forecasting. Physica A 280(3-4): 497-504.

Woodford, M. (2009) Convergence in macroeconomics: Elements of the new synthesis. American Economic Journal: Macroeconomics 1(1): 267-279. 